\title{
Processo ensino-aprendizagem na residência médica
}

\author{
The teaching-learning process in medical \\ residency
}

Sérgio Henrique de Oliveira Botti ${ }^{\mathrm{I}}$

Sergio Rego ${ }^{\mathrm{II}}$

PALAVRAS-CHAVE

- Internato e Residência

- Capacitação profissional

- Ensino

- Aprendizagem

\section{KEY WORDS}

- Internship and Residency

- Professional training

- Teaching

- Learning
Recebido em: 24/11/2008 Reencaminhado em: 04/04/2009 Aprovado em: 26/07/2009

\begin{abstract}
R E S U M O
A comunidade científica nacional e internacional discute muito sobre o ensino médico e o equilíbrio entre conhecimento científico, raciocínio clínico, desenvolvimento de habilidades práticas, formação do caráter e profissionalismo. Entretanto, em nosso meio, o processo ensino-aprendizagem é pouco estudado durante a residência médica. Pretendemos descrever as relações da ciência da aprendizagem com o ensino durante a residência médica. Analisamos essa interface em publicações nacionais e internacionais da área da educação em geral, da educação médica e da residência no período compreendido entre 1997 e 2007, mostrando os pressupostos da aprendizagem importantes no desenvolvimento do raciocínio clínico, no ensino de habilidades e na aquisição de competências indispensáveis à formação do residente.
\end{abstract}

\section{A B S T R A C T}

The Brazilian and international scientific communities have engaged in extensive debate on the balance between scientific knowledge, clinical reasoning, development of practical skills, character-building, and professionalism. However, the teaching-learning process during medical residency has received little research attention in Brazil. This article aims to describe the relations between the science of learning and teaching during medical residency. We analyze this interface in Brazilian and international publications (1997-2007) from the field of education in general, medical education, and medical residency, demonstrating the important learning assumptions in the development of clinical reasoning, teaching of skills, and acquisition of indispensable competencies for the resident's training.

\footnotetext{
${ }^{I}$ Universidade Federal de Juiz de Fora, Juiz de Fora, MG, Brasil.

${ }^{I I}$ Fundação Oswaldo Cruz, Rio de Janeiro, RJ, Brasil.
} 


\section{INTRODUÇÃO}

O ensino médico na graduação é objeto de intensa produção acadêmica nacional e internacional, tendo como um de seus temas principais o delicado equilíbrio entre foco no conhecimento científico, raciocínio clínico, desenvolvimento de habilidades práticas, formação do caráter e profissionalismo ${ }^{1-6}$. Em nosso país, embora o curso ainda seja terminal ${ }^{7-10}$, ou seja, sua conclusão habilita o recém-graduado a exercer a profissão, reconhece-se que a residência médica exerce uma função que muitas vezes extrapola o que seria de esperar de uma formação de pós-graduação. Ainda se busca o equilíbrio entre a formação científica oferecida pelas faculdades e uma formação que desenvolva as competências e habilidades indispensáveis à prática médica ${ }^{11}$. Os recém-formados procuram, então, a residência médica como continuação de sua formação ${ }^{12}$, embora nem todos logrem obter uma vaga. A responsabilidade de preceptores e docentes envolvidos na residência médica aumenta, e se torna ainda mais relevante discutir como se dá o processo de ensino-aprendizagem nessa modalidade de pós-graduação.

A residência representa mais que uma busca de aperfeiçoamento da competência profissional adquirida na escola. Ao ingressar nessa pós-graduação, procura-se treinamento em alguma especialidade; aquisição progressiva de responsabilidade pelos atos profissionais; desenvolvimento da capacidade de iniciativa, julgamento e avaliação; internalização de preceitos e normas éticas; e o desenvolvimento de espírito crítico ${ }^{8,12,13}$. Todas essas funções fazem com que a residência médica represente um marco profundo no perfil profissional do futuro médico 9 .

Contudo, apesar dessa importância, o processo de ensino-aprendizagem durante a residência ${ }^{9,14,15}$ é ainda pouco estudado. A maioria dos trabalhos existentes discute, quase exclusivamente, a titulação do corpo docente, as condições de trabalho dos residentes e a organização dos programas. O conteúdo da formação, como deve ser esse processo, como os residentes aprendem eo que eles aprendem ainda são muito pouco discutidos ${ }^{9,16}$.

Um dos principais atributos da expertise médica é identificar, entre as informações colhidas do paciente e entre os achados do exame físico, dados pertinentes para a construção de um diagnóstico de trabalho que contemple o desenvolvimento de estratégias de ação adequadas ao caso ${ }^{17,18}$. Aliado a esse atributo fundamental, Lipkin ${ }^{19}$ cita que o bom médico deve ainda ter compreensão precisa e completa do doente e da doença, conhecimento profundo e pessoal da história de cada pessoa que o procura, capacidade de ouvir e escutar, empatia, compromisso e respeito (atributos relacionais). A formação durante a residência pretende desenvolver os atributos técnicos e também os atributos relacionais (comportamentos e atitudes) em busca do profissionalismo que marca profundamente a medicina ${ }^{3-5}$.
O exercício e, consequentemente, o ensino da profissão médica se encontram diante de algumas encruzilhadas, afirma Lipkin ${ }^{19}$. O autor relata que se exige dos médicos, principalmente daqueles em formação, que sejam breves, objetivos, que venham ao centro dos assuntos e apresentem questões complexas de forma resumida e concisa. Por outro lado, sustenta que alguns esperam, dos médicos, desenvolvimento dos atributos relacionais, que aprimoram o contato profissional com as pessoas. Apesar de muitos acreditarem que essa última visão é uma utopia, alguns afirmam que faz parte dos elementos críticos da melhor medicina ${ }^{19}$.

Outro conflito citado pelo autor está entre buscar os padrões institucionais - satisfação do paciente para que ele retorne, eficiência, custo-efetividade e redução dos riscos para a própria instituição - que mantêm viva a organização e tornam os médicos mais rápidos e mais "baratos" ou econômicos, ou procurar atitudes, comportamentos, conhecimentos e princípios que levem a um bom desempenho da "melhor medicina"19. Para Lipkin ${ }^{19}$, esta "melhor medicina" é a aquela que queremos para as pessoas de quem mais gostamos.

Podemos ainda adicionar o conflito entre o diagnóstico clínico, baseado em entrevista e exame físico, e a excessiva importância dada à tecnologia, defendida pelo complexo médico-industrial. $\mathrm{McGe}^{20}$ afirma que quanto mais precoce na formação médica, maior ênfase se dá ao treinamento de habilidades clínicas e que, posteriormente, essa importância vai diminuindo enquanto se fortalece a dependência e o crédito nos exames complementares.

Entendemos que abordar esses conflitos e as questões educacionais no âmbito da residência é essencial para uma melhoria na formação médica em nosso meio. Num momento em que muito se fala sobre a medicina baseada em evidências, não podemos acreditar que encontramos nela uma receita pronta para a profissão ${ }^{20}$. Segundo $\mathrm{McGee}^{20}$, existem muitas sutilezas no encontro entre um médico e seu paciente que os estudos clínicos não conseguem atingir e que nenhum teste ou manobra, por maior acurácia que tenham, conseguem suplantar.

Então, como acontece o raciocínio que constrói as decisões clínicas e que leva aos comportamentos e atitudes? E mais, como se ensina e como se aprende essas competências e atributos durante a residência? A literatura internacional oferece vários estudos sobre esse modo como os médicos raciocinam e chegam aos diagnósticos ${ }^{17,21-23}$ e como podem aprender comportamentos e atitudes pertinentes a uma boa prática ${ }^{1,19,24}$. O propósito desta revisão é contribuir para qualificar ainda mais a discussão sobre a residência médica em nosso país, buscando sistematizar de forma crítica contribuições da ciência da aprendizagem para esta modalidade de pós-graduação médica. 


\section{MÉTODOS}

Foi realizada uma revisão não sistemática da bibliografia disponível mediante consulta nas bases de dados PubMed (da National Library of Medicine - www.pubmed.org), Scielo (Scientific Eletronic Library on Line) e Biblioteca Virtual da Saúde (http://regional.bvsalud.org/php/index.php?lang=pt). Na pesquisa foram utilizados os seguintes conjuntos de descritores: medical residency e learning; teaching e clinical reasoning; pedagogical e medical education; professionalism e medical education; e clinical competence. A pesquisa foi realizada também com os descritores em português. Os focos principais da revisão foram: desenvolvimento do raciocínio clínico, ensino de habilidades e aquisição de competências indispensáveis à formação do residente. Os artigos obtidos foram analisados inicialmente de acordo com seus títulos e em seguida por seus resumos e separados quando versavam sobre o tema específico dessa revisão. Os artigos que melhor atenderam aos critérios foram lidos e, quando confirmada a especificidade desejada, foram verificadas suas próprias referências. Foram consultados igualmente livros especializados na temática pretendida, garantindo, assim, a inclusão de obras de referência nesta revisão.

\section{RESULTADOS E DISCUSSÃO}

\section{Uma nova ciência da aprendizagem}

Aprender é adquirir conhecimentos, habilidades, compreensão. Significa ainda "agarrar" intelectualmente ${ }^{25}$. Para Teixeira ${ }^{26}$, até o século 20, aprender significava "fixar um fato ou uma habilidade na memória ou no hábito". Saviani ${ }^{27}$ afirma que a escola tinha a formação intelectual como o centro, tendo o professor o papel primordial de transmitir os conhecimentos, e os alunos, o de assimilá-los.

Ocorre, então, uma evolução no sentido do aprender. O que inicialmente significava apenas memorizar passa a ter o sentido de compreender o que havia memorizado. Depois, aprender torna-se formular com palavras próprias o que se havia compreendido. Mais tarde ainda, segundo Teixeira ${ }^{26}$, aprender assume o significado de "ganhar um modo de agir", isto é, a aprendizagem só ocorre quando, após assimilarmos algo, conseguimos agir de acordo com o que aprendemos. Aprender, nessa concepção, é um processo ativo que se desenvolve a partir da seleção de reações apropriadas, que depois são fixadas ${ }^{26}$. Não se aprende apenas por absorção. O cerne do ensino é transferido da compreensão intelectual para a prática, do lógico para o psicológico, e dos conteúdos para os processos ${ }^{27}$.
Mas como conseguimos aprender? Grandes são os esforços que tentam relacionar os achados das pesquisas e a prática no dia a dia da escola. Os estudos das últimas décadas do século 20 influenciaram e modificaram a educação ${ }^{28}$. Educar é muito mais do que treinar. Treinar, segundo Houaiss ${ }^{25}$, tem origem no francês traîner, usado inicialmente no português como termo de volataria, com o sentido principal de adestrar, condicionar, domesticar, arrastar, levar alguém à força. Aqui, em sintonia com Struchiner e Giannella (p.4) ${ }^{29}$, entendemos educação como um "processo de transmissão, construção e reconstrução do conhecimento e da formação de cidadãos competentes e conscientes de seu papel em nossa sociedade, capazes de atuarem produtivamente e de forma comprometida em seus ambientes sociais e em suas atividades profissionais".

Quanto ao ensino-aprendizagem de habilidades médicas, sabemos que a coordenação de diversas formas de conhecimentos é necessária durante o desenvolvimento do raciocínio diagnóstico e de atitudes profissionais, sendo mais importante que qualquer outra habilidade ou tarefa mental isolada ${ }^{19,21,30}$. Estudos mostram que conhecimentos sobre as ciências básicas; sobre os scripts das doenças (sinais, sintomas, apresentações típicas, qualificadores semânticos como bilateral/unilateral, simétrico/assimétrico); os esquemas mentais que os relacionam (matrizes com suas probabilidades ou árvores de decisões) e conhecimentos advindos da experiência (o aprender com a prática clínica, com exemplos passados) são coordenados, num processo que se torna mais importante que o uso isolado de qualquer um desses itens ${ }^{23,31}$. Norman ${ }^{31}$ chama esse processo de coordenação de "raciocínio clínico".

Vários modelos que tentam explicar esse raciocínio diagnóstico são descritos na literatura ${ }^{30,32,33}$. Elstein e Schwarz ${ }^{33}$ mostram que a estratégia usada na solução de problemas clínicos depende da dificuldade encontrada e do conhecimento adquirido, sendo que as conclusões finais vão depender tanto desse conhecimento quanto da força das evidências (raciocínio clínico baseado em evidências). A intuição clínica e a teoria das probabilidades são utilizadas nesse processo que consiste em testar hipóteses, comparar com padrões já estabelecidos e categorizá-las ${ }^{33}$. Custer et al. ${ }^{30} \mathrm{e}^{\text {Bordage }} \mathrm{e}^{23}$ destacam três principais teorias que explicam o raciocínio clínico: estruturada em protótipos, num processo de abstração que constrói uma via comum de pensamento a partir da experiência com outros pacientes; estruturada em exemplos, na qual exemplos de pacientes são memorizados, se mantêm imutáveis e são utilizados quando necessário, sem nenhuma abstração; e estruturada numa rede semântica de esquemas e scripts, representada por numerosos nós (menores unida- 
des do conhecimento) conectados por elos, na qual a estrutura e a função do conhecimento estão intimamente relacionadas, e que é ativada por estímulos específicos para determinados nós.

Poucos são os estudos que analisam esses modelos de explicação do raciocínio clínico de maneira não excludente, caracterizando-o como multifatorial, combinado e flexível ${ }^{18,21}$. Ark et al..$^{21}$ e Eva ${ }^{17}$ também afirmam que o uso de estratégia de raciocínio que combina vários fatores é bem mais efetivo que o uso de um ou outro componente isolado. $\mathrm{O}$ raciocínio clínico confere ao médico, frente a um paciente, uma visão própria e específica do caso. No encontro clínico, o profissional vai construindo várias questões e vai tecendo respostas que levam a determinada direção. Porém, os médicos experientes não conseguem explicar facilmente como chegam ao diagnóstico final, pois essa tarefa não depende exclusivamente de conhecimentos específicos ${ }^{34}$.

Remetendo-nos ao sistema educacional, não é mais seu objetivo a simples aquisição de habilidades literárias, como ler, escrever e calcular, nem mesmo a aquisição exclusiva de conhecimentos específicos. O mundo complexo e global em que vivemos já exige das pessoas essas condições. A educação preocupa-se em estimular o pensamento, a leitura crítica, a expressão clara e contundente de ideias e opiniões, e a solução de problemas reais ${ }^{28}$. No ensino da medicina, tanto na graduação quanto na residência, conhecimentos e habilidades isolados não tornam um médico competente, mas, sim, a capacidade de usar esses atributos, quando necessário, em situações clínicas particula$\mathrm{res}^{34}$. E, ainda, para um bom desempenho da medicina, sabemos serem necessárias, além de competências técnicas, a satisfação profissional, a satisfação dos pacientes e uma atenção de qualidade, que seja eficiente e custo-efetiva. Isso exige comportamentos, atitudes, conhecimentos e princípios cientificamente comprovados, que podem e devem ser desenvolvidos durante a residência médica ${ }^{1,19}$.

A ciência da aprendizagem construiu uma teoria que aborda o currículo, o aprender/ensinar e a avaliação de maneira muito diversa da que estamos acostumados a praticar no cotidiano de nossas escolas ${ }^{28}$. Essa teoria dá maior importância às relações traçadas entre alunos e professores. Nesse sentido, o Ministério da Saúde, em relação ao ensino médico, privilegia posturas ativas, críticas e reflexivas, que incentivem a abertura de caminhos para a transformação e não para a reprodução acrítica da realidade social ${ }^{35}$. Tal pensamento ganhou mais força por ser o resultado de um trabalho multidisciplinar, que envolve pensadores da ciência da cognição, da psicologia social, da antropologia, da neurociência, utiliza modelos computadorizados e conta com professores de grande experiência prática. Esse trabalho conjunto contribui para encontrar resultados importantes, factíveis e com a capacidade de mudar e melhorar a prática educacional, buscando, como afirma Simon (p.115) ${ }^{36}$, a "aplicação da nova ciência da aprendizagem no ensino e aprendizagem das ciências".
A humanidade sempre conviveu com o ensinar e o aprender, mas a revolução cognitiva nos leva a uma nova visão. Ela respeita o conhecimento prático já adquirido e contribui com considerações que aperfeiçoam e enriquecem os fundamentos desse processo. Compreender profundamente como conhecemos, aprendemos e ensinamos é importante para desenvolver ou perseguir o potencial pessoal e profissional de cada um. E, cada vez mais, conseguimos subsídios que nos permitem aprofundar nessa compreensão ${ }^{36}$.

A medicina combina características de arte e de ciência. Nesse ambiente, o residente observa os preceptores, tomando-os como modelo não apenas de conhecimento e de habilidades técnicas, mas também como espelhos de comportamentos e atitu$\mathrm{des}^{1}$. E esse processo pelo qual adquirem conhecimentos, habilidades e valores, e começam a aprender a exercer o seu papel na sociedade é chamado de formação da identidade profissional ${ }^{24}$, que se inicia desde a graduação e continua na residência médica.

Sabemos que existe grande diferença, no processo cognitivo, entre decorar e entender, e assim compreendemos melhor a formação da identidade médica, que se relaciona mais com o entender. Quem entende algo tem a capacidade de reter esse conhecimento por um período de tempo mais longo e de usá-lo, quando pertinente, em novas situações ${ }^{36}$. Podemos, com isso, considerar que o primeiro passo no caminho do ensino-aprendizagem durante a residência é explicitar o que deve ser compreendido e o que o aprendiz deve ser capaz de fazer com o que compreendeu $^{15}$. A base dessa compreensão, afirma Simon ${ }^{36}$, são regras procedimentais do tipo "se... então", que devem ser internalizadas pelo médico em formação, para demonstrar o conhecimento e as habilidades objetivados. O segundo passo é oferecer experiências variadas que permitam ao residente aprender a captar pistas ou sinais relevantes nas situações encontradas e a buscar, na memória, ações apropriadas, efetivas e pertinentes para serem usadas em situações posteriores ${ }^{36}$.

Durante a residência, a aprendizagem deve ser significativa, com seus objetivos bem explícitos, para que possa motivar o residente $^{15}$. Simon ${ }^{36}$, falando sobre educação em geral, afirma que a motivação pode vir da descoberta, do deixar descobrir. E que o oferecimento de um ambiente no qual novos conhecimentos e habilidades são obtidos regularmente é um ponto essencial. Um bom caminho a seguir é, então, orientar o médico recém-formado a fazer sucessivas descobertas e ofertar exemplos que o façam perceber a existência de alguns padrões, para tomar atitudes pertinentes; e deixar bem claros os objetivos da aprendizagem ${ }^{15}$.

\section{O raciocínio clínico}

A residência médica, segundo Huddle e Heudebert ${ }^{34}$, deve mostrar a importância de perceber os aspectos essenciais e não se confundir com características superficiais e supérfluas dos ca- 
sos clínicos. É preciso estar dentro do contexto, discriminando os fatores relevantes daqueles não muito importantes. E, ainda, é necessário que o residente aprenda a construir questões pertinentes a cada caso, mesmo que ainda não saiba as respostas. Estas serão atingidas com o tempo e serão guardadas na memória com muito mais sucesso do que as respostas/ensinamentos que não forem oriundos de questões próprias ${ }^{34}$.

Simon $^{36}$ afirma que a escola nos mostra apenas uma das muitas maneiras de aprender. Isto é, a escola não é o único local onde aprendemos. A educação formal já não consegue mais oferecer tudo, e um de seus objetivos é, então, desenvolver o potencial de cada um, por meio de ferramentas intelectuais e estratégias de aprendizagem que ensinam a aprender e que serão usadas por toda a vida ${ }^{28,36}$. A grande preocupação de que a escola simplesmente seleciona talentos e não os desenvolve é combatida mediante novas práticas educacionais. Mesmo aqueles bons alunos nos métodos tradicionais de ensino ganham em desenvolvimento de habilidades, conhecimentos e atitudes com essas novas práticas ${ }^{28}$.

A residência pode ser um espaço para se aprender a habilidade de utilizar várias abordagens na resolução de um caso clínico, o que faz parte da expertise médica. Para compreendermos melhor, recorremos a Ark et al..$^{37}$, que afirmam que, no raciocínio clínico, o médico lança mão de dois tipos de mecanismos não excludentes, operacionalizados de várias maneiras: analítico e não analítico. O mecanismo analítico é representado por considerações sistemáticas, que podem ser controladas. Estas se relacionam a características isoladas dos fatores que levam à construção dos diagnósticos (por exemplo: edema mole, frio e indolor). Isso é o tradicionalmente ensinado, dando especial atenção à identificação de todas as características clínicas e ao seguimento de algoritmos para se traçar a hipótese diagnóstica ${ }^{37}$. Huddle e Heudebert ${ }^{34}$ o chamam de conhecimento da medicina e suas técnicas.

Esse mecanismo analítico do raciocínio clínico tem como base a concepção behaviorista de conhecimento, considerando que este vem do mundo externo ao sujeito, já pronto e acabado ${ }^{28}$. Então, entraria através dos sentidos e se fixaria, independendo da vontade do indivíduo. Conhecer, para um behaviorista, é descobrir. E essa descoberta já está presente no mundo externo, por isso o homem é produto do meio onde vive ${ }^{38}$. No mesmo caminho, para a abordagem tecnicista da educação, que tem suas origens no pensamento behaviorista, a organização sistemática dos conteúdos, as técnicas e os recursos são os principais fatores do processo de aprendizagem. Isso, porque essa abordagem acredita que somente esses fatores podem ser explicitados pela ciência, por meio de comprovação e validação empíricas. Então, educar é transmitir conhecimentos, habilidades, práticas sociais e comportamentos, numa tentativa de controlar o ambiente, a cultura e a sociedade. E a escola, local onde se dá o processo formal de educação, ensina de acordo com as condutas úteis e desejáveis para a sociedade, privilegiando o planejamento e a organização, buscando objetivos determinados previamente e que possam ser mensurados, e oferecendo o feedback necessário, como reforço às respostas dos estudantes. Com esse reforço, tem-se a garantia de que o conhecimento e as condutas vão se enraizar e se tornar permanentes ${ }^{38}$. É a base do ensino por módulos, no qual o aprendiz realiza uma experiência individual e no seu ritmo, muito comum durante a graduação e que persiste na residência. O professor tem, nessa abordagem, a função de planejar, avaliar e elaborar os materiais para possibilitar que todos, ao final, cheguem ao mesmo objetivo.

Já os mecanismos não analíticos do raciocínio clínico, explicitados no fim do século 20 por Norman e Brooks ${ }^{32}$, são representados pelas considerações diagnósticas feitas, rápida e inconscientemente, a partir de similaridades do caso atual com outros do passado, num fenômeno que pode ser denominado reconhecimento padrão ${ }^{29}$. Não quer dizer que seja necessário que o médico em formação construa protótipos e os guarde na memória. Os protótipos existem. Mas decorar listas de sinais e sintomas e, a partir deles, tentar encontrar um diagnóstico não deve ser a base do ensino médico, como tem acontecido nos últimos anos. Existem outras instâncias importantes para o raciocínio, que permitem identificar, manipular e dar nova interpretação ao que foi guardado na memória, sem respeitar regras explícitas ou conferir pesos predeterminados aos mais variados fatores. Isso foi comprovado por estudos em que modelos computacionais, com enorme capacidade de acúmulo de informações e de regras para utilizá-las, apresentaram pior desempenho que pessoas experientes ${ }^{32}$.

Percebemos que o sucesso no raciocínio clínico depende da abordagem do paciente como um todo, reinterpretando as características isoladas à luz desse todo ${ }^{32}$. Os conhecimentos da medicina e as técnicas são ferramentas importantíssimas, que devem ser usadas na apreensão dos pacientes, dentro de seus contextos $^{34}$. Entendemos, ainda, que esse raciocínio utiliza mecanismo analítico e não analítico conjuntamente e pode ser treinado, ensinado e aprendido na residência médica, por meio de táticas instrucionais adequadas ${ }^{32,37}$. A experiência pode ser compreendida como uma familiaridade com vários exemplos, e o ensino durante a residência deve organizar as experiências dos neófitos para conseguir o máximo de eficiência da aprendizagem. Isso não depende de qualquer regra ou heurística, mas de métodos que arranjem a sequência de exemplos de modo que o residente possa caminhar da identificação das características de determi- 
nado protótipo até a comparação com exemplos de outras condições, explicitando semelhanças e diferenças. $\mathrm{O}$ ambiente e o modo como se dá essa formação são de suma importância: aprende-se muito mais com o estímulo para chegar a um diagnóstico levando em conta seus diferenciais do que com uma simples arguição de variados diagnósticos diferenciais em exemplos fixos e estanques ${ }^{32}$.

\section{O raciocínio clínico e o construtivismo}

Os fundamentos que explicam o raciocínio clínico são encontrados na chamada nova ciência do conhecimento. Novas ferramentas, metodologias e teorias possibilitaram a exploração das funções mentais relacionadas ao pensamento e à aprendizagem no decorrer da segunda metade do século 20. Associa-se, a esses avanços, a compreensão da importância dos contextos sociais e culturais no processo de ensino-aprendizagem ${ }^{28}$.

A capacidade de compreender passa a ser essencial para a aprendizagem. Intuitivamente, sempre se deu importância à compreensão, mas historicamente ela foi pouco estudada. Ao mesmo tempo, a escola cobra mais memória que compreensão, oferecendo conteúdos e uma grande quantidade de conhecimentos que os estudantes devem decorar, o que podemos perceber também durante a residência. As novas teorias concedem importância a um corpo de conhecimentos estruturados, mas afirmam também que mais importante é a conexão entre os conteúdos desse conhecimento, sua organização em conceitos, a percepção dos contextos em que podem ser utilizados e a possibilidade de transferência para outros contextos, quando pertinente ${ }^{28}$.

Focalizando o ensino médico durante a residência, Whit$\mathrm{comb}^{41}$ afirma que apenas competências informativas, baseadas no domínio de conhecimentos, habilidades e atitudes clínicas, não conferem a um residente a qualidade de ser um bom profissional. Para isso, é necessário que o médico em formação consiga traduzir essas competências e integrá-las, de maneira a desempenhar tarefas complexas, que caracterizam uma atividade médica de qualidade. Nesse sentido, a residência deve oferecer oportunidades clínicas variadas para que os neófitos exerçam o cuidado aos pacientes nas diversas circunstâncias da vida de um médico $^{34,39}$. Não deve exigir apenas atributos cognitivos dos residentes, mas estimular que eles cuidem bem de seus pacientes nas situações clínicas reais ${ }^{40}$. O treinamento desses atributos cognitivos isolados pode anatomizar o cuidado médico, o que é prejudicial à qualidade da atenção. A ênfase nas competências informativas não consegue evidenciar a habilidade médica de escolher, entre os elementos dessas competências, aqueles que devem ser utilizados em cada situação ${ }^{34}$. E, segundo Huddle e Heudebert $^{34}$, essa habilidade essencial para um bom profissional só é conseguida se treinada durante a residência médica, des- tacando o cuidado do paciente como um todo e não o treinamento de habilidades isoladas.

Para Bransford et al. $^{28}$, esse importante ponto das teorias da aprendizagem, o foco na compreensão, leva a um estudo minucioso do processo do conhecimento, das teorias de Piaget e Vygotsky. Para eles, todos chegam à escola com conhecimentos prévios, crenças, conceitos e habilidades já adquiridos que influenciam sua maneira de ver o mundo, de percebê-lo e de interpretá-lo. Então, esses fatores agem em seus atributos de memória, raciocínio, solução de problemas e no processo de aquisição de novos conhecimentos ${ }^{28}$.É o construtivismo, essa teoria que acredita que as pessoas são aprendizes ativos, que procuram o conhecimento e trazem consigo uma série de fatores e conhecimentos adquiridos que vão compor o seu ponto de vista sobre os diversos cenários de aprendizagem. A partir dessas características próprias, constroem novos conhecimentos e compreendem novos assuntos ${ }^{41}$.

Na prática, isso afirma a preocupação do ensino com os conceitos já trazidos e com o entendimento, a interpretação e as convicções que o estudante tem com base nesses conceitos (que podem ser ou não corretos, exatos, precisos). A escola amadurece esses conceitos, conferindo-lhes maior precisão e acurácia. Alguns confundem esse pensamento construtivista, retirando toda a função de ensinar da escola, como se o estudante aprendesse isoladamente, por si só. Não é isso. O construtivismo afirma que o ensino pode e deve mostrar diretamente os caminhos e os conceitos, mas que eles serão reinterpretados pelos estudantes e que devemos ter especial atenção para essas interpretações ${ }^{28}$.

Huddle e Heudebert ${ }^{34}$ posicionam esse pensamento construtivista dentro do ensino durante a residência médica por meio do conceito de "reflexão na ação", proposto por Schon ${ }^{42}$. Os autores caracterizam o trabalho médico como uma construção de um problema, como um raciocínio feito com base no conhecimento específico, em técnicas e na capacidade de percepção do outro e de seu mundo (do paciente). Portanto, um processo que traz muito de ambos (do médico e do paciente) ${ }^{34}$. E afirmam, ainda, que o ensino dessa habilidade não pode ser fragmentado em vários elementos. $\mathrm{O}$ que se espera do residente como competência geral é que ele se arme de conhecimentos e técnicas específicos, mas que consiga responder, com eles, aos diferentes pacientes que vai encontrar em sua vida profissional, pacientes com diferentes contextos. Porque o que realmente se pretende com a residência é que ela traga ao futuro médico o domínio de uma série de competências que respondam às necessidades da sociedade e a capacidade de integrá-las em sua prática profissional $^{43}$.

Kipper e Loch ${ }^{44}$ afirmam que a residência médica deve aperfeiçoar as competências adquiridas na graduação. Isto é, o residente deve aprimorar o comportamento ético em suas relações; 
sua percepção dos determinantes socioculturais, político-econômicos e biopsíquicos do processo saúde e doença; sua compreensão da diversidade de comportamentos, ideias e crenças; seu domínio em realizar procedimentos clínicos e cirúrgicos indispensáveis ao médico geral e ao especialista; e sua habilidade de comunicação, empatia e trabalho em equipe ${ }^{45}$. Nesse ponto, o papel do preceptor é crucial, pois só alguém que acompanhe realmente o residente em suas atividades diárias poderá ficar atento ao ensino-aprendizagem dessas competências ${ }^{34}$.

Outro fator importante no construtivismo é a metacognição, isto é, a capacidade do estudante de perceber, avaliar e controlar seu processo de aprendizagem e sua performance em desempenhar tarefas. É o aprendiz desenvolvendo um diálogo interno e percebendo o próprio entender, as novas informações imprescindíveis à compreensão, o quanto são coerentes com os conceitos adquiridos previamente e como construir analogias que o auxiliem em todo esse processo. A metacognição é um forte componente da expertise adaptativa. Estimulá-la é um dos papéis da escola e auxilia no desenvolvimento da capacidade de transferência de conhecimentos para novas situações, quando se julga necessário que isso ocorra ${ }^{28}$.

Klass ${ }^{41}$ aponta que essa é uma das maiores mudanças no ensino médico: examinar a própria prática, acompanhar o processo ensino-aprendizagem e buscar as necessidades educacionais. Seguindo esse pensamento, podemos afirmar que o residente deve desenvolver a capacidade de metacognição com base em suas atividades práticas, refletindo sobre elas e buscando novas competências que ele julgue necessárias para melhorar sua performance como médico. Isso, segundo Ten Cate e Scheele ${ }^{45}$, ajudaria a diminuir a distância entre a teoria e a prática no ensino durante a residência médica e levaria a um ensino-aprendizagem baseado na competência, no qual atingir os resultados seria mais importante que cumprir determinado tempo de treinamento.

Percebemos que a escola precisa trabalhar com o conhecimento prévio do aluno, criando espaço para que esse conhecimento seja explicitado. $\mathrm{O}$ ensino deve, ainda, ter um foco que abarque desde a atividade, o processo de produção e o produto, estimulando a execução de determinadas tarefas (supervisionando a quantidade e qualidade do trabalho); passando pelo foco na aprendizagem ao desempenhar a tarefa (preocupando-se com o que o neófito está aprendendo durante a execução da tarefa e com os passos seguidos); até chegar ao foco na percepção de todo o processo por quem está aprendendo (preocupando-se com o que está aprendendo, mas com especial atenção ao feedback para o estudante sobre todo o processo de aprendiza- gem e sobre qual o propósito, o passo inicial que levou à execução da tarefa) ${ }^{28}$. Esse pensamento está ligado ao ensino de competências, tão discutido na formação profissional.

Ten Cate e Scheele ${ }^{45}$ afirmam que o residente deve adquirir uma competência profissional, que representa muito mais do que a soma de competências operacionais detalhadas (atividades importantes que devem fazer parte do ensino, como interpretar determinado exame complementar ou entrevistar um paciente). Na verdade, os residentes devem adquirir, durante seu processo de ensino-aprendizagem, além de competências operacionais, atributos gerais de um médico, que são uma gama de qualidades que um bom profissional deve ter. Isto é, além das atividades específicas que caracterizam a profissão e que devem fazer parte da residência médica, existem atributos gerais que permitem que o médico em formação execute essas atividades independentemente, sem auxílio de um preceptor, a partir de certo momento de sua formação. Esses atributos devem ser adquiridos na prática clínica diária durante a aprendizagem na residência ${ }^{45}$.

\section{CONCLUSÕES}

Na nova ciência da aprendizagem, aprender significa agir de maneira diferente. Encarar a formação profissional durante a residência médica como um processo educacional é considerá-la algo mais que um treinamento. E esse processo se baseia no desenvolvimento coordenado de diversas formas de conhecimentos e habilidades, e na aquisição de atributos técnicos e relacionais.

Para que essa formação profissional tenha sucesso, a aprendizagem deve ser significativa e com objetivos bem explicitados. Na aquisição da expertise médica, o residente deve adquirir habilidades para aprimorar seu raciocínio clínico, utilizando mecanismos analíticos e não analíticos, traduzindo as competências informativas e conseguindo integrá-las, o que lhe permite desempenhar tarefas complexas exigidas pela profissão.

Outro fator importante para o êxito da aprendizagem durantea residência é a ênfase na metacognição. Por meio desse exercício, o residente vai adquirindo atributos técnicos e relacionais que lhe permitem se responsabilizar progressivamente pelos atos profissionais, até que não precise mais da ajuda do preceptor.

Acreditamos, então, que o desenvolvimento de competências médicas específicas, de habilidades clínicas e da identidade profissional baseado em princípios da nova ciência da aprendizagem e nas pesquisas em educação médica encontra, na residência, terreno fértil e adequado ao seu crescimento em qualidade. Nesse caminho, percebemos que estaremos no sentido certo para a construção de uma medicina melhor. 


\section{REFERÊNCIAS}

1. Branch WT, Kern D, Haidet P, Weissmann P, Gracey CF, Mitchell G et al. Teaching the human dimensions of care in clinical settings. JAMA. 2001;286:1067-1074.

2. Cooke M, Irby DM, Sullivan W, Ludmerer KM. American Medical Education 100 Years after the Flexner Report. N Engl J Med. 2006;355(13):1339- 1344.

3. Mufson MA. Professionalism in medicine: the department chair's perspective on medical students and residents. Am J Med. 1997;103:253-255.

4. Stephenson AE, Adshead LE, Higgs RH. The teaching of professional attitudes within UK medical schools: reported difficulties and good practice. Med Educ. 2006; 40: 1072-1080.

5. Swick HM, Szenas P, Danoff D, Whitcomb ME. Teaching professionalism in undergraduate medical education. JAMA. 1999;282:830-832.

6. Ministério da Saúde. Secretaria de Políticas de Saúde. Uma nova escola médica para um novo sistema de saúde. Saúde e Educação lançam programa para mudar o currículo de medicina. Rev Saúde Pública. 2002;36(3):375-378.

7. Brasil. Decreto no 20931 de 11 de Janeiro de 1932. Regula e fiscaliza o exercício da medicina, da odontologia, da medicina veterinária e das profissões de farmacêutico, parteira e enfermeira, no Brasil, e estabelece penas. Diário Oficial da União [documento na internet], 15 jan. 1932. [acesso em 27 abr. 2008]. Disponível em: http://www.jusbrasil.com.br/legislacao/116714/decreto-20931-32

8. Chaves MM, Rosa AR (Org.) Federação Pan-Americana de Faculdades e Escolas de Medicina. Educação médica nas Américas: o desafio dos anos 90. São Paulo: Cortez; 1999.

9. Feuerwerker LCM. Mudanças na educação médica e residência médica no Brasil. Interface Comun Saúde Educ. 1998;2(3):51-71.

10. Stella RCR, Goldenberg P, Gomes MHA, Goihman S. Graduação médica e especialização: uma incompatibilidade aparente. Rev Assoc Med Bras 1997;43(4):290-294.

11. Stern D. Minimum Competencies for Medical Graduates: a Global Affair. XVII Panamerican Conference on Medical Education; 2006 april 20; Santo Domingo, Dominican Republic: [s. n.]; 2006.

12. Martins LAN. Residência médica: estresse e crescimento. São Paulo: Casa do Psicólogo; 2005.

13. Ministério da Educação. Secretaria de Ensino Superior. Residência médica [acesso em 06 jul. 2006]. Disponível em http:/ / portal.mec.gov.br/index.php?option=com_content\&view $=$ article\&id $=12263 \&$ Itemid $=506$

14. Calil LC. Proposta de um modelo pedagógico para programas de residência médica. Rev Bras Med. 2000;57(7):751-756

15. Teunissen PW, Boor K, Scherpbier AJJA, Van der Vleuten CPM, Van Diemen-Steenvoorde JAAM, Van Luijk SJ, et al. Attending doctors' perspectives on how residents learn. Med Educ. 2007;41:1050-1058.

16. Feuerwerker LCM. Avaliação da residência médica em São Paulo. Cad Fundap. 1996; 19:153-169.

17. Eva KW. What every teacher needs to know about clinical reasoning. Med Educ. 2004; 39:98-106.

18. Montgomery K. How doctors think: clinical judgment and practice of medicine. New York: Oxford University Press; 2006.

19. Lipkin M. Foreword. In: Coulehan JL, Block MR. The Medical Interview: mastering skills for clinical practice. Philadelphia: F.A.Davis; 2006. p.ix-xi.

20. McGee S. Evidence based physical diagnosis. St Louis, Missouri: Saunders Elsevier; 2007.

21. Ark KT, Brooks LR, Eva KW. The benefits of flexibility the pedagogical value of instructions to adopt multifaceted diagnostic reasoning strategies. Med Educ. 2007;41:281-287.

22. Rikers RMJP, Verkoeijen PPJL. Clinical expertise research: a history lesson from those who wrote it. Med Educ. 2007;41:1115-1116.

23. Bordage G. Prototypes and semantic qualifiers: from past to present. Med Educ. 2007; 41:1117-1121.

24. Hafferty F W. Professionalism: the Next Wave. N Engl J Med. 2006; 355(20):2151-2152.

25. Houaiss A, Villar MS. Dicionário Houaiss da Língua Portuguesa. Rio de Janeiro: Objetiva; 2001.

26. Teixeira A. Pequena introdução à filosofia da educação: a escola progressiva ou a transformação da escola. Rio de Janeiro: DP\&A; 2000.

27. Saviani D. As concepções pedagógicas na história da educação brasileira. In: Lombardi JC, Saviani D, Nascimento MIM. Navegando pela História da Educação Brasileira. [CD-ROM online]. Campinas: UNICAMP/HISTEDBR; 2006. [acesso em: 10 dez. 2007]. Disponível em: http:/ / www.histedbr.fae.unicamp.br/navegando/artigos_frames/artigo_036.html.

28. Bransford JD, Brown AL, Cocking RR, (Eds.). How people learn: brain, mind, and school. Expanded Edition. Washington, DC: Nacional Academies Press; 2000. 
29. Struchiner M, Giannella TR. Formação de profissionais de saúde e educação à distância: elementos fundamentais. In: Castro JL, (Org.). PROFAE: educação profissional em saúde e cidadania. Brasília: Ministério da Saúde; 2002. p.1-21.

30. Custers EJ, Regehr G, Norman GR. Mental representations of medical diagnostic knowledge: a review. Acad Med. 1996;71(10):S55-61.

31. Norman G. Research in clinical reasoning: past history and current trends. Med Educ. 2005;39:418-427

32. Norman GR, Brooks LR. The Non-Analytical Basis of Clinical Reasoning. Adv Health Sci Educ Theory Pract. 1997;2:173-184.

33. Elstein AS, Schwarz A. Evidence base of clinical diagnosis:clinical problem solving and diagnostic decision making: selective review of the cognitive literature. BMJ. 2002;324:729-732.

34. Huddle TS, Heudebert GR. Taking Apart the Art: The Risk of Anatomizing Clinical Competence. Acad Med. 2007;82:536-541.

35. Ministério da Saúde. Secretaria de Gestão do Trabalho e da Educação na Saúde. Departamento de Gestão da Educação na Saúde. Caminhos para a mudança da formação e desenvolvimento dos profissionais de saúde: diretrizes para a ação política para assegurar Educação Permanente no SUS. Brasília: Ministério da Saúde; 2003.

36. Simon, HA. Observations on the sciences of science learning. J Appl Dev Psychol. 2000;21(1):115-121.

37. Ark TK, Brooks LR, Eva KW. Giving Learners the Best of Both Worlds: Do Clinical Teachers Need to Guard Against Teaching Pattern Recognition to Novices? Acad Med. 2006;81:405-409

38. Struchiner M, Giannella TR. Aprendizaje y práctica docente em el área de la salud. Conceptos, paradigmas e innovaciones. Washington, DC: OPS; 2005.

39. Waldrop MM. Humanity 2, computers 0; chess champion Gary Kasparov's human imagination beats the brute-force computer tactics of Deep Thought. Science 1989; 246(4930):572-573.
40. Whitcomb ME. Redirecting the Assessment of Clinical Competence. Acad Med. 2007;82 (6):527-528.

41. Klass D. A Performance-Based Conception of Competence is Changing the Regulation of Physicians' Professional Behavior. Acad Med. 2007;82:529-535.

42. Schon DA. Educating the reflective practitioner. [online] meeting of the American Educational Research Association;1987 April. 20-24; Washington, DC. [acess 2007 Jun. 28]. Available at: http://resources.educ.queensu.ca/ar/schon87.htm.

43. Rousseau A, Saucier D, Côté L. Introduction to Core Competencies in Residency: Description of an Intensive, Integrated, Multispecialty Teaching Program. Acad Med. 2007; 82:563-568.

44. Kipper DJ, Loch JA. Questionamentos éticos relativos à graduação e à residência médica. Rev Bioet. 2002;10:107-128.

45. Ten Cate O, Scheele F. Competency-Based Postgraduate Training: can We Bridge the Gap between Theory and Clinical Practice? Acad Med. 2007; 82:542-547.

\section{CONTRIBUIÇÃO DOS AUTORES}

Sérgio Henrique de Oliveira Botti realizou a revisão bibliográfica, a primeira redação e participou da redação final do trabalho. Sergio Rego realizou a revisão da primeira redação, a discussão do texto e também participou da redação final do trabalho.

\section{CONFLITO DE INTERESSES}

Declarou não haver.

\section{ENDEREÇO PARA CORRESPONDÊNCIA}

Hospital Universitário da Universidade Federal de Juiz de Fora.

Av. Eugênio do Nascimento s $/ n^{\circ}, 3^{\circ}$ andar, CORE.

Dom Bosco - Juiz de Fora

CEP. 36038-330 - MG

E-mail: botti@uai.com.br 